\title{
The spatial dimensions of neighbourhood: How older people define it
}

\begin{abstract}
This paper seeks to develop our understanding of neighbourhood boundaries, as defined by older people. Using interview and mapping methods, research revealed the significance of three factors: built-form pattern, spatial distribution of the social networks, and personal attributes, as contributing to how older people define their neighbourhood boundaries. Research findings highlighted discrepancies between residents' perceived neighbourhood boundaries and the statistical unit used as the neighbourhood proxy in most neighbourhoodrelated research. The findings suggested that the statistical information about the neighbourhood effects on older people does not necessarily reflect the lived experience of older people in their perceived neighbourhood.
\end{abstract}

Keywords: neighbourhood boundary, older people, social network, master planned community. 


\section{Introduction}

It is now well established that neighbourhoods contribute to a wide range of outcomes for their residents (Gibbons 2002; Goux and Maurin 2007; Ziersch et al. 2005). Although many studies have recognised the importance of the neighbourhood, they have had difficulty in defining a standardised and operational neighbourhood boundary (Flowerdew, Manley, and Sabel 2008). Most of the studies into neighbourhood effects have used readily available geographical data units such as statistical area level 2 (SA2) in Australia (Badland et al. 2013), ward in the United Kingdom (McCulloch and Joshi 2001), and census tract in the United States (Balfour and Kaplan 2002). These definitions may not coincide with how the neighbourhood is defined by its residents. The difference between the lived experience and statistical definitions of what a neighbourhood is, potentially causes spatial analysis problems (Campbell et al. 2009; Coulton et al. 2001), and results in significant information biases, which decreases the trustworthiness of the research findings (Lebel, Pampalon, and Villeneuve 2007; Spielman and Yoo 2009). For instance, Duncan et al. (2014) defined youths' spatial accessibility to tobacco retailers on the basis of different neighbourhood definitions, including circular and network buffers of 400 metres and 800 metres, census block groups and census tracts. The findings suggested that the use of larger administrative neighbourhood definitions causes bias in the estimates of neighbourhood exposure to tobacco retailers among youths.

Neighbourhood boundary is a subjective concept (Campbell et al. 2009; Guest and Lee 1984; Lee and Campbell 1997). Multiple factors, including demographic characteristics (Campbell et al. 2009; Orford and Leigh 2014), can contribute to how residents define the boundaries of their neighbourhoods. Older people's perceived neighbourhood boundaries might be different from those of a younger age cohort. A limited but growing body of research has demonstrated the ways in which a neighbourhood affects older people, especially their health and wellbeing (Yen, Michael, and Perdue 2009). However, the ways in which older people perceive their neighbourhood boundaries has not received any research attention. In order to understand how the neighbourhood impacts on older people, the first step is to identify how neighbourhood boundaries are defined by this age cohort.

The neighbourhood is particularly important in the social lives of older people. Due to a lessening in competence and reduced activity range in later years (Oswald et al. 2005), older people tend to spend a large proportion of their time within their own neighbourhoods 
(Phillips et al. 2005), and thus a great deal of their social lives, including social interactions with other people, takes place in that area (Godfrey, Townsend, and Denby 2004). An investigation of the social lives of older people is thus an essential area of study in research into the definitions of neighbourhood boundaries.

In addition, it is important to investigate the characteristics of the built environment in which older people are living when researching how they define their neighbourhood boundaries. This is an important area of research with regard to the diversity of the built forms within each census-defined neighbourhood unit. In this respect, a quickly expanding type of housing development, known as the Master Planned Community (MPC), requires specific research attention. With their distinct built form, ownership arrangements, governance and social infrastructure (Cheshire et al. 2010; Minnery and Bajracharya 1999), MPCs have different characteristics from conventional suburbs, although they may be embraced by the same census-defined neighbourhood unit.

This paper seeks to identify the perceived neighbourhood boundaries of older people with respect to the spatial distribution of their social networks and the built-form patterns in which they are living. Research methods included interviews and mapping. The data on the perceived neighbourhood boundaries of the participants was analysed using Kevin Lynch's (1960) model of the structure of urban perception. The research was conducted in four case study areas with different built-form patterns, including different types of MPC developments and conventional suburbs, located in the city of the Gold Coast, Queensland, Australia.

This paper is structured as follows: firstly, it reviews the literature on neighbourhood meaning and the measurement of neighbourhood boundaries. Secondly, the research methods and methodology are described. This is followed by the research findings, which reveal some associations between the perceived neighbourhood boundaries of older people and the spatial distribution of their social networks, the built-form patterns in which they are living, as well as their personal characteristics.

\section{Conceptualisations of the neighbourhood and its boundary}

Urban terminology is complex and as Rybczynski $(1995,176)$ stated, “one reason that it's not easy to clearly identify what has happened and is happening to cities is that urban terminology is very inaccurate”. This is particularly true about the term 'neighbourhood'. In spite of the long tradition of neighbourhood research, scholars have not reached a consensus on how to define neighbourhood nor have they agreed on a definition of its physical 
boundary. The conceptualisation of the neighbourhood dates back to the beginning of the 20th century, when the Chicago School characterised the neighbourhood as being a "natural area”, “a locality with sentiments, traditions, and a history of its own” (Park et al. 1925, 6). However, as Spielman and Yoo (2009) argued, there is nothing organic about the neighbourhood boundaries being used in many current studies.

A large number of studies have used Census Bureau or other administrative units as the neighbourhood boundaries (Sampson et al. 2002), mainly due to the availability of data (Coulton et al. 2001; Dietz 2002; Lebel, Pampalon, and Villeneuve 2007). It has been argued that these pre-defined neighbourhood boundaries are incomplete since they often fail to reflect the "complex conceptualisation of neighbourhoods" (Lupton 2003, 3). Explaining the complexity of neighbourhood conceptualisation, Lupton (2003) pointed to three factors: firstly, the neighbourhood concept incorporates both place and people, and neighbourhood characteristics are influenced by the interaction between place and people. Secondly, a neighbourhood is not a fixed entity. It has subjective characteristics which are not experienced in the same way by all people. Thirdly, a neighbourhood is not isolated. Neighbourhood characteristics are shaped in relationship to other places as well as by the neighbourhood's internal features (Lupton 2003, 4).

Some recent studies have considered alternatives to conceptualise neighbourhood boundaries in order to address the complexity of the concept of neighbourhood. For instance, Lebel, Pampalon, and Villeneuve (2007) utilised a new approach to defining neighbourhood boundaries, based on the integration of several elements including the history of the area, its socioeconomic status, and how it is perceived by local key actors. In another example, IMPACT (Inner-City Mental Health Study Predicting HIV/AIDS, Club and Other Drug Transitions) introduced a multistep neighbourhood boundary definition process which included a development of census block group maps, accompanied by a review of land use and census tract data. These methods were utilised along with an observation of each of the targeted areas (Weiss et al. 2007). Although innovative, these methods of defining neighbourhood boundaries have not been free from limitations. They have not taken into consideration the perceptions of residents. Nor have they considered the heterogeneity of residents, particularly in relation to age groups which affect the way they perceive their neighbourhood and how they define its boundary. 
There is no well-established method for using residents' perceptions in neighbourhood boundary definitions. Some recent studies used mapping as a means of identifying residents' perceived neighbourhood boundaries (Campbell et al. 2009; Coulton et al. 2001; Smith et al. 2010). The use of individuals' maps or boundary definitions has a long tradition in urban sociology and environmental psychology (Downs and Stea 1973; Keller 1968). An influential study in this area is Kevin Lynch's (1960) book, 'The Image of the City'. Lynch argued that people use mental maps to navigate through the city. Lynch's (1960) methodology and findings showed that people's mental maps of cities include five fundamental elements: paths, edges, districts, nodes and landmarks. According to Lynch (1960), paths are the channels in the city such as streets, walkways and canals. Edges are defined as the linear elements such as boundaries between two phases which break up the continuity of the city. Some examples are shores, edges of developments and walls. Districts are the medium-tolarge segments of the city which have some common and identifying characteristics. Nodes refer to the strategic spots in the city which range from junctions, such as the crossing of paths, to concentrations of some characteristics or activities such as an enclosed square, a street corner hangout or a building. Finally, landmarks are physical objects such as a building, a sign or a mountain, with some key elements including singularity or contrast with the background. Landmarks have some unique or memorable aspects which make them easily identifiable in cities (Lynch 1960).

Lynch's study revealed the complicated relationships between person and place. His methodology has the potential to be used in analysing residents' neighbourhood boundary maps and helps in identifying how older people perceive their neighbourhood boundaries. Nevertheless, the use of the mapping method in identifying residents' perceived neighbourhood boundaries is not free of weakness. Mapping only reflects the geographic dimension of the neighbourhood. Mapping fails to reflect the neighbourhood social life and the effects that the neighbourhood social life has on how residents define their neighbourhood boundaries. It is notable that the neighbourhood is not purely a geographic concept. Social life has been implicit in a large number of existing definitions of the neighbourhood (see for example Davies and Herbert [1993]; Guest and Lee [1984]; Meegan and Mitchell [2001]). Therefore it would be useful to incorporate the spatial distribution of social networks into the definition of the neighbourhood boundary. This is particularly the case in respect to the ways in which older people define their neighbourhood boundaries, as a great deal of their social life occurs in their neighbourhood environment (Godfrey, Townsend, and Denby 2004). The 
study of the spatial distribution of the social network along with the neighbourhood boundary maps drawn by older people would be useful to illustrate both the social and physical dimensions of the perceived neighbourhood boundaries of older people.

\section{Case studies}

Data for this research was collected from different built-form patterns in four case study areas located in the city of the Gold Coast, Queensland, Australia. Figure 1 illustrates how the built-form patterns are classified. The first group, conventional suburbs, are characteristic Australian suburbs comprised of detached, semi-detached and attached housing, located in cul-de-sacs or grid street patterns. The second group, MPCs, are characterised as large scale, private sector driven housing estates, which come with a marketed lifestyle package, including community, safety, recreational facilities, and open space or landscaping features (Cheshire et al. 2010; Minnery and Bajracharya 1999). As illustrated in Figure 1, MPCs can be either mixed-age or age-segregated and they take a variety of built forms, including highrise apartment buildings, as well as gated and non-gated developments. The main difference between high-rise apartments and the other types of MPCs (gated and non-gated developments) is the arrangement of residences. High-rise apartments are comprised of residential units located on different floors, and connected with corridors, lifts and stairways as shared spaces. However, gated and non-gated developments include mainly attached, and in a few cases semi-detached and detached housing, located along low-speed streets and other open spaces (e.g., green spaces), shared by all residents of the development.

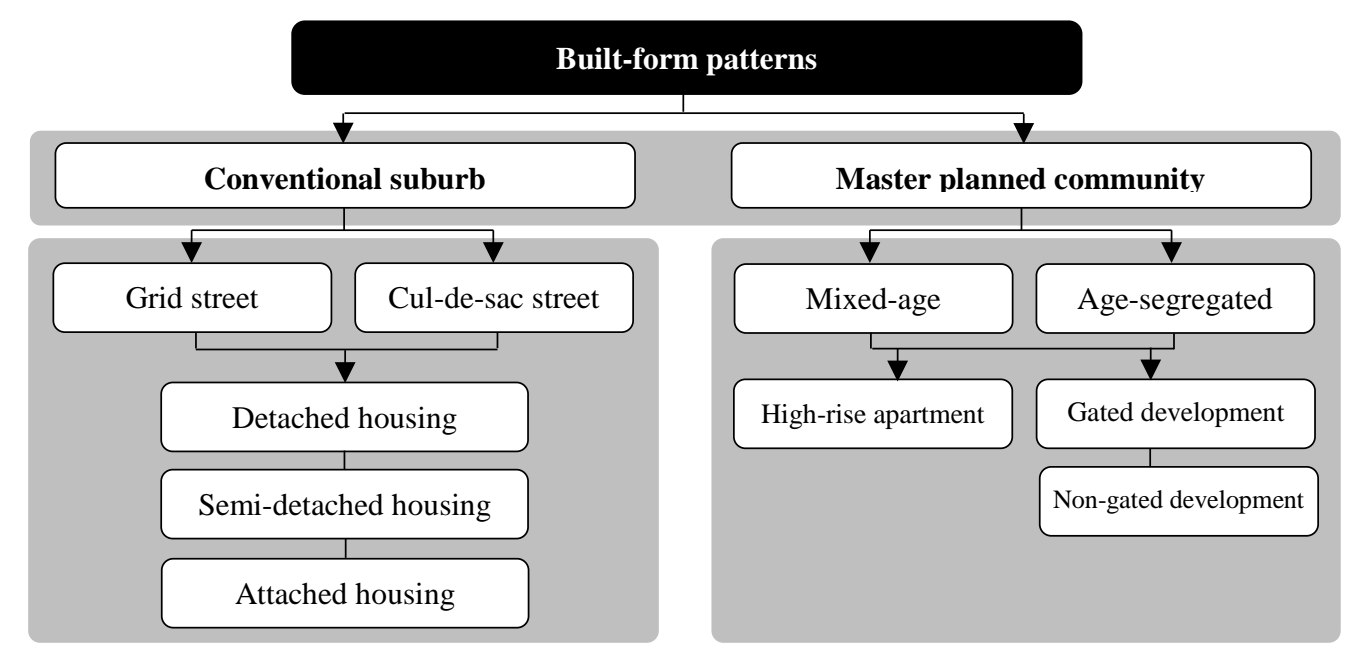

Figure 1. Built-form pattern categories in this paper. 
The four case study areas were census-defined units, known as statistical areas level 2 (SA2s). The SA2 is a geographic unit defined by the Australian Statistical Geography Standard (ASGS). It represents a community consisting of an average of 10,000 people, who interact both economically and socially (ABS 2011a). The case study areas included Southport, Mermaid Waters, Clear Island Waters and Hope Island (see Figure 2). While all case study areas had a high ageing population profile (ABS 2011b), they were diverse in their built form. Southport is a relatively densely populated area by Gold Coast standards, with 18.11 persons per hectare (ABS 2011b). It is a mixed-use area with predominantly conventional built-form pattern. Southport has a grid street pattern and is mainly comprised of older detached, and more recent semi-detached and attached housing. There are also a few MPCs, including high-rise apartments and gated and non-gated developments in this case study area. Mermaid Waters and Clear Island Waters are residential suburbs with a population density of 18.30 and 9.44 persons per hectare, respectively (ABS 2011b). They are comprised of a conventional built-form with cul-de-sac street network pattern. Hope Island, on the other hand, is a residential suburb with a relatively low population density of 5.93 persons per hectare (ABS 2011b). It comprises several gated developments, a few of which are age-segregated. The street network pattern of this case study area is mainly cul-desac. Figure 2 illustrates some information including the population density, the proportion of detached housing, and the median age in the four case study areas. 


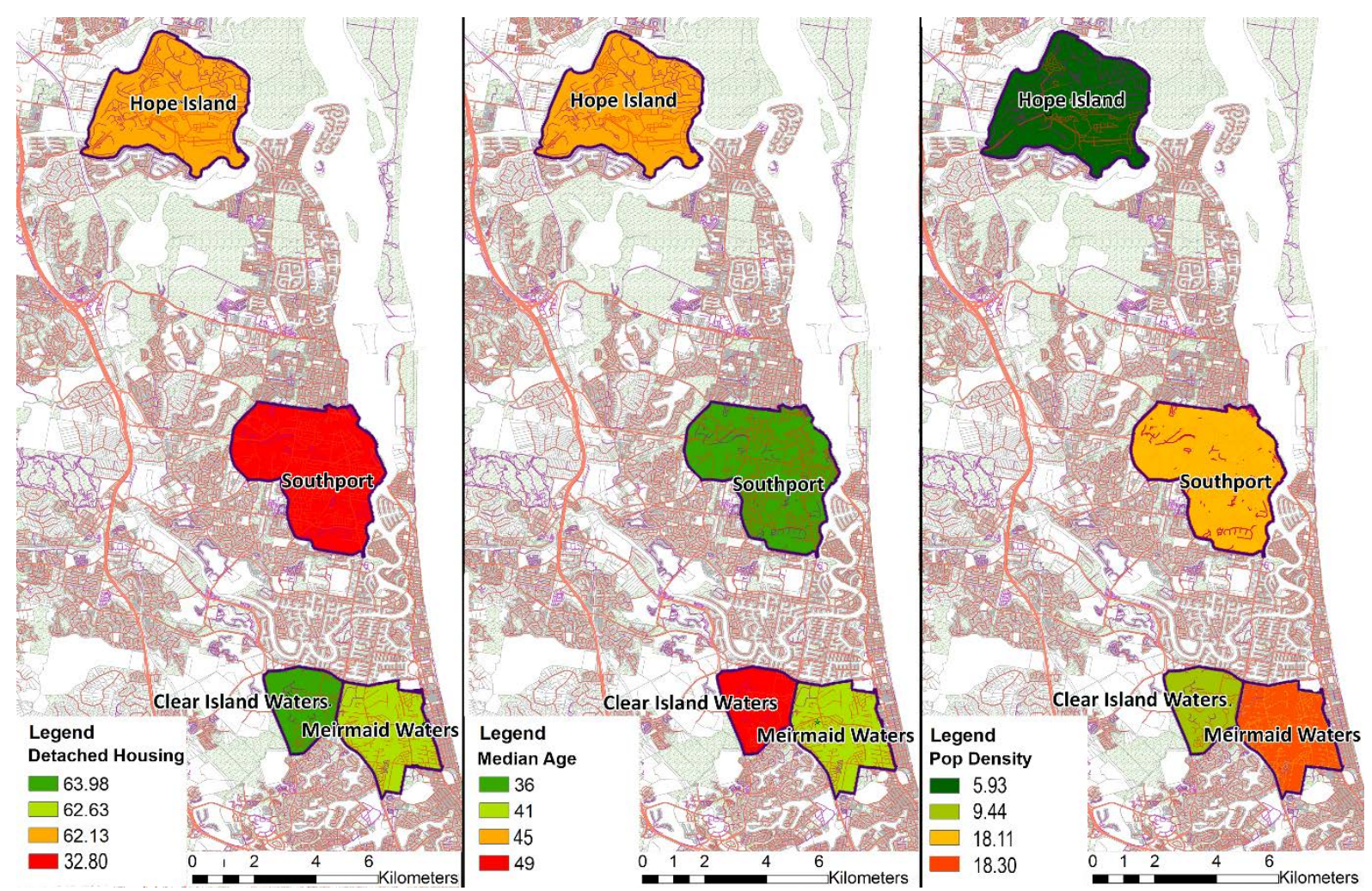

Figure 2. Population density (persons per hectare), proportion of detached housing (percentage), and median age (year) in the four case study areas (ABS 2011b).

\section{Data collection}

Adopting a qualitative approach, this research aims to fill the gaps in the neighbourhood boundary definition literature. In contrast to the majority of the research in this field which has sought to quantify the neighbourhood boundary definition, this paper applied qualitative methodologies to provide an in-depth description of how older people define the boundaries of their neighbourhoods. It investigated the subjective views of neighbourhood boundaries in a sample of 54 older people (aged 65 years or over). Data was collected through semistructured interviews and mapping. Ethics approval was granted by the Griffith University Ethics Committee to undertake the interviews (Reference no: ENV/42/14/HREC). The interviews were conducted in a face-to-face setting, either at the participants' homes or at a location of their choice. Participants were recruited through a combination of methods: letterbox drops, convenience, and snowball sampling. They remained anonymous and were given pseudonyms to ensure confidentiality. The participants constituted 21 men and 33 women, ranging in age from 65 to 94 years. They had been living in their current residences from 4 months to 32 years. Forty participants were from some type of MPC developments while 14 were living in conventional suburbs. They were all either retired or aged pensioners 
with 30 doing some type of voluntary work. A few participants reported some degree of limitation in walking ability. However, all but one were physically active and had the ability to physically walk out of their homes to some extent (see Table 1 for a summary of participants’ profiles).

\begin{tabular}{|c|c|c|c|c|c|}
\hline & Southport & $\begin{array}{l}\text { Mermaid } \\
\text { Waters }\end{array}$ & $\begin{array}{l}\text { Clear Island } \\
\text { Waters }\end{array}$ & Hope Island & Total \\
\hline Number & 19 & 14 & 6 & 15 & 54 \\
\hline \multicolumn{6}{|l|}{ Age } \\
\hline Least & 67 & 65 & 71 & 67 & 65 \\
\hline Most & 94 & 87 & 85 & 90 & 94 \\
\hline Mean & 75.95 & 65.81 & 78.83 & 77 & 76.37 \\
\hline Median & 74 & 73.50 & 79.50 & 77 & 75 \\
\hline \multicolumn{6}{|l|}{ Gender } \\
\hline Male & 4 & 5 & 3 & 9 & 21 \\
\hline Female & 15 & 9 & 3 & 6 & 33 \\
\hline \multicolumn{6}{|l|}{ Employment status } \\
\hline Retired & 19 & 14 & 6 & 15 & 54 \\
\hline Doing some type of paid work & 2 & 1 & 0 & 0 & 3 \\
\hline Doing some type of volunteer work & 12 & 7 & 5 & 6 & 30 \\
\hline \multicolumn{6}{|l|}{ Neighbourhood pattern: } \\
\hline Conventional suburban housing--grid street & 9 & 0 & 0 & 0 & 9 \\
\hline Conventional suburban housing--cul-de-sac & 0 & 4 & 1 & 0 & 5 \\
\hline Gated development (age-segregated) & 0 & 0 & 0 & 10 & 10 \\
\hline Gated development (mixed-age) & 0 & 0 & 0 & 5 & 5 \\
\hline Non-gated development (age-segregated) & 7 & 2 & 5 & 0 & 14 \\
\hline Non-gated development (mixed-age) & 0 & 1 & 0 & 0 & 1 \\
\hline High-rise apartment (age-segregated) & 1 & 0 & 0 & 0 & 1 \\
\hline High-rise apartment (mixed-age) & 2 & 7 & 0 & 0 & 9 \\
\hline \multicolumn{6}{|l|}{ Number of residents at home } \\
\hline 1 & 15 & 7 & 2 & 2 & 26 \\
\hline 2 & 4 & 7 & 4 & 13 & 28 \\
\hline
\end{tabular}

participants.

The participants were first asked to explain how they defined their neighbourhood boundaries. The intention of the question was to identify the iconic places/spaces or particular activities and people that characterised the neighbourhood boundaries. The respondents were then referred to the map of the case study area, which had been extracted from Google Maps and printed on A3 paper. Google Maps was used as it was likely to be familiar to participants and thus could help them navigate through the map more easily. The A3 paper size was chosen because it was small enough to be followed easily by the participants. At the same time, the size of the map was large enough to show sufficient detail of the area including the street names, along with a few landmarks, such as shopping centres and tram lines, to help orientate the respondents. The interviewer, with the help of the respondents, located the respondents' homes on the map. The respondents were then asked to draw what they believed was their neighbourhood boundary. They were assured that 'neighbourhood' is a subjective concept and their perceptions were of interest and there was no correct or incorrect answer. 
Respondents were then asked questions about their social lives. Social life was measured based on the three types of ties or relationships: strong, weak and absent ties (Granovetter 1973). According to Granovetter (1973), strong ties or friendships are the most intense types of relationships concentrated within clusters of friends. Weak ties, known as the relationships with acquaintances, are not as intense as strong ties and they bridge different clusters of strong ties. Finally, absent ties lack any significant social relationship and refer to, for example, the acknowledgment relationships between people living in the same neighbourhood or those residing on the same street.

Participants were asked to point out on the map of their case study areas where the people with whom they had strong ties were living and where they met them. Participants were not aware of where all of people with whom they had weak and absent ties lived. They were thus asked to locate on the map where they usually saw these people. Figure 3 illustrates two maps as examples, each showing the perceived neighbourhood boundaries, neighbourhood nodes and the spatial distribution of social networks, drawn by two different participants. This type of data from the maps drawn by all 54 participants was traced into ArcMap 10.2. Further information from the interviews was then added to the maps created in ArcMap 10.2, where applicable. The associations between the perceived neighbourhood boundary of each participant and the spatial distribution of his/her social network were investigated. The analysis, at this stage, was conducted separately for each participant. Then the data from all maps were overlayed and the perceived neighbourhood boundaries of all participants were compared with each other. The comparisons were particularly focused on the perceived neighbourhood boundaries of older people living in different built-form patterns associated with the four case study areas. At each stage, the findings were recorded as notes (textual data) to be further analysed together with the interview data.

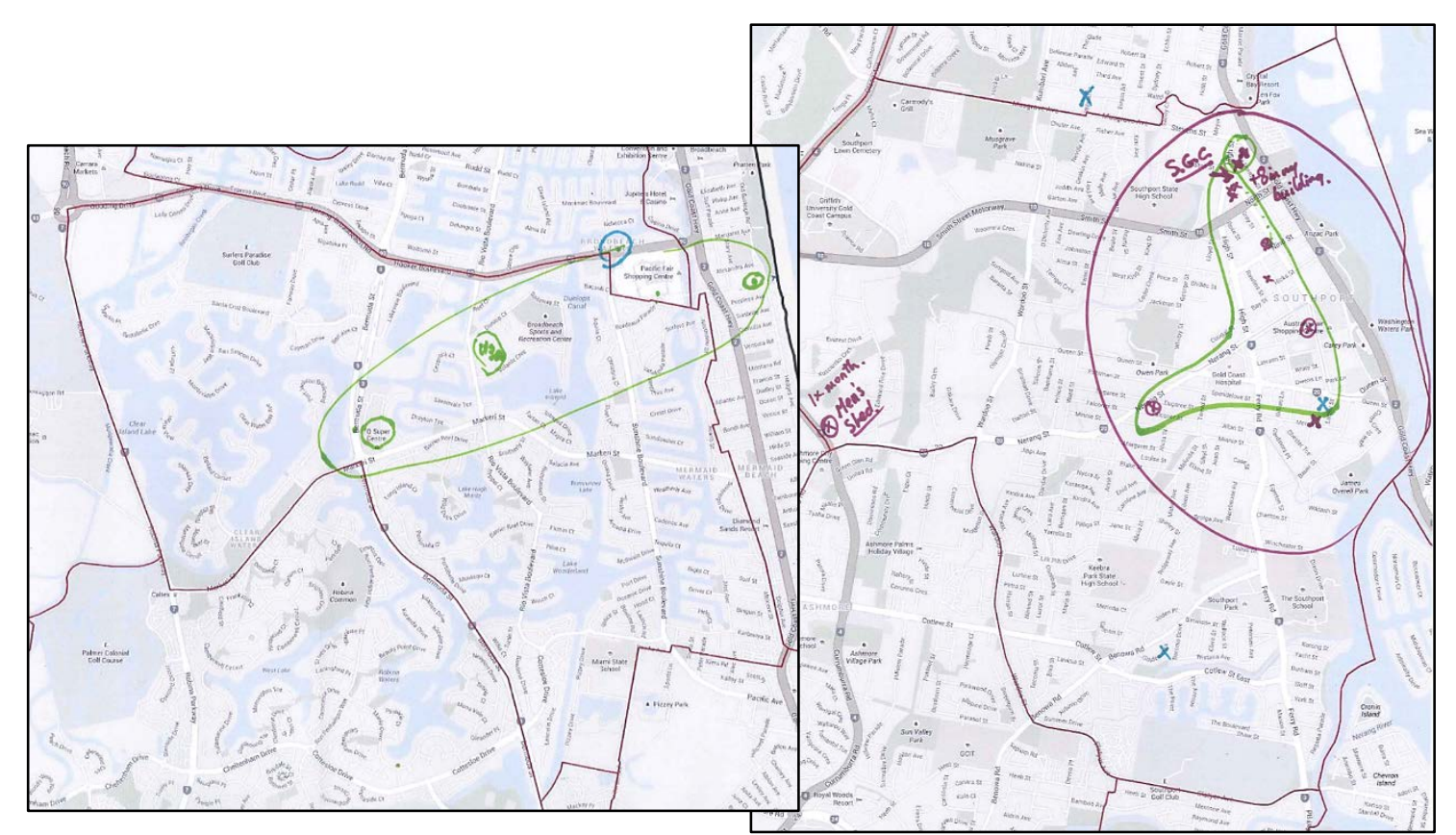


Figure 3. Examples of the mapping method used to record the perceived neighbourhood boundaries, neighbourhood nodes and the spatial distribution of the social networks of older people (left: Mermaid Waters, right: Southport).

Data from the interviews and notes from analysing the maps were further analysed using QSR NVivo 10 data management software. The data was coded to highlight themes and subthemes that characterise how participants defined their neighbourhood boundaries. The coding process involved an immersion into the data, applying both inductive and deductive approaches. This means that the coding process not only focused on testing themes extracted from the literature (deductive approach), but it also allowed new themes to emerge (inductive approach) (Berg and Lune 2004). Once the data was coded, it was transformed into meaningful findings through a search for any associations, contradictions, similarities and differences across the various types of themes and sub-themes. The findings revealed indepth information about the perceived neighbourhood boundaries of older people. The next section describes different factors found to be important in participants' definitions of neighbourhood boundaries.

\section{Analysis framework: Using Lynch's model}

Participants defined their neighbourhood boundary by using different features of the environment. The features ranged from a street to various places such as a school or a shopping centre. The features which our participants used to define their neighbourhood boundaries were in line with one or more of Lynch's (1960) elements of the perceptual form of cities. Some participants referred to paths as a means of defining their neighbourhood boundaries. For example, Barbara's neighbourhood stopped at a busy road which discouraged her from walking beyond it. She said:

...probably because I've got to walk over that busy road, I feel that the busy road cuts me off that [the area beyond the road] little bit... [and] I sort of feel I'm slightly indifferent to that [the area beyond the road]. 
Edges were also used as a main determinant of the neighbourhood boundary. A great number of MPC residents referred to the boundary of the MPC development as their neighbourhood boundary. This was the case for all types of MPC developments, either gated or non-gated, as they all had a distinctive boundary (physical or perceived) to their surrounding environment. In addition, a few participants from Hope Island referred to the boundary of Hope Island as being their neighbourhood boundary. Hope Island, in comparison to the other three case study areas, has a distinctive boundary, as it is an island separated from the rest of the Gold Coast. James referred to the whole Hope Island as his neighbourhood and explained:

Well, I cross the bridge down there and cross the bridge there I am out of Hope Island. Hope Island is in fact an island, surrounded by water, so the creek and the river runs around Hope Island, so wherever the river is, that is the boundary of Hope Island.

Some participants also referred to districts as defining their neighbourhood boundaries. Richard divided Southport into three zones: smart (high class), central, and low class. He considered the low class zone as his neighbourhood:

That is my neighbourhood... I know I don't live in the smart end of Southport. This is a smart end down here, Southport Central at that end. I am in the northern end.

For Martha, however, landmarks played an important role in defining her neighbourhood boundary:

My neighbourhood is limited to maybe TSS [The Southport School] and Australia Fair [Shopping Centre]. That is sort of where I am. My grandson went to TSS. It is like a landmark, and then Brickworks [shopping precinct] came. Brickworks was built, that was another one. Because I have been around for a while, Australia Fair started to sort of open up, but the TSS has always been there That was a landmark when you came down to the coast... that is what I consider...

An element which almost all participants referred to as marking the boundaries of their neighbourhoods was a node. The nodes included a wide variety of places with different functions. Some participants, especially those living in MPC developments, referred to the nodes as having social functions which included the places where they socialised with others. 
Some others, particularly those living in conventional suburbs, referred to the nodes as having physical functions, which included the places where they undertook their day-to-day activities such as walking or shopping. The number and spatial distribution of nodes referred to by each participant were also found to be indicative of the size of participants' perceived neighbourhood boundaries. Our research suggested that the function (whether social or physical), number and spatial distribution of the nodes referred to by participants were influenced by some factors, including the built-form pattern in which the participants were living, the spatial distribution of their social networks, and their own social and physical attributes. These are discussed in the next section.

\section{Neighbourhood nodes, built-form patterns and the spatial distribution of social networks}

\section{MPC developments}

In general, participants from MPC developments put great emphasis on their social lives in the neighbourhood and they tended to refer to the nodes as having social functions to define their neighbourhood boundary. For a large number of MPC participants, the social ties within the MPC played a key role in defining the boundaries of their neighbourhoods, and thus the MPC development comprised the main node marking the perceived neighbourhood boundary. Nevertheless, not all MPC participants put equal emphasis on the MPC social ties when defining their perceived neighbourhood boundaries. This largely varied with respect to the type of MPC in which they were residing, the characteristics of the built environment surrounding the MPC, as well as the personal attributes of participants.

\section{Age-segregated MPC developments}

The residents of age-segregated MPCs put the greatest emphasis on their social ties within the MPC to define their neighbourhood boundaries. These participants had a relatively large number of strong, weak and absent ties with fellow residents in the MPC, and in most cases their social networks did not go far beyond the physical boundaries of the MPC developments. A high number of social ties within the age-segregated MPC developments was particularly seen among those living in gated and non-gated developments, as well as those who had moved to the MPC from other cities/suburbs, left behind their social networks, and had to rebuild social ties within their new living environment. 
The research revealed that the lifestyle offered by many age-segregated MPCs included a wide range of social events and activities open to all residents. Due to the age structure of the age-segregated MPCs, the residents tended to spend a great deal of their time within the developments and to engage in the social events and activities on offer. In this way residents were provided with a range of opportunities to establish a high number of social ties with fellow residents. The establishment of social ties in age-segregated MPCs was further encouraged through the planning and design of the houses, as well as the provision of the shared open spaces in gated and non-gated developments. The houses in the gated and nongated developments were located around low-speed shared streets and open spaces where a high level of safety from crime, along with the provision of safe pedestrian infrastructure, encouraged walking. On the other hand, the provision of soft edges (Gehl 1986), such as porches and front gardens as transitional areas, linked private spaces (homes) to public areas, including MPC's streets and open spaces. The space connection between the home and its surrounding environment was found to encourage social interaction between households and fellow residents in the MPC's open spaces. The majority of this social interaction occurred between MPC residents while they were walking within the development, gardening or spending time in front of their homes, and usually led to the establishment of absent, weak and eventually strong ties. In this respect, Amy stated:

...if you are going for a walk, and somebody was in the garden, you would say hello and maybe have a chat with them, whoever they might be, whether you know their name or whether you don't. Because everybody in here is pretty friendly...

As a result of a high level of social engagement with fellow residents, the perceived neighbourhood boundary of age-segregated MPC residents was, in most cases, restricted to one node, which was the MPC development. Lisa, for instance, mentioned:

... [My neighbourhood is] probably the immediate village mostly. I wouldn't say that we would know many people outside, apart from some people who come to catch the bus sometimes and we get to talk to them. Yeah generally sort of this village.

Only in a few cases did participants refer to a second node, such as a shopping centre or a green space located adjacent to the age-segregated MPC, which they attended regularly. These were particularly seen in the case of participants from age-segregated MPCs that were 
located in mixed-use urban environments. Figures 4, 5, and 6 present the land use classifications in the case study areas. Figures 7, 8, and 9 also show the walking distance service areas of $400 \mathrm{~m}, 800 \mathrm{~m}$ and $1600 \mathrm{~m}$ from each MCP development. It is notable that these figures do not include the data associated with all participants, as doing so would have made the maps confusing and difficult to read. The orange lines on these figures present a graphic illustration of the perceived neighbourhood boundaries of some participants from agesegregated MPCs. The figures show that the participants from mixed use urban environments, such as Southport, where there are commercial activities in the walking distance of the agesegregated MPCs, tended to include the MPC and its surrounding commercial activities, such as the shopping centres, in their perceived neighbourhood boundaries. The findings stress that not only the characteristics of the MPC, including its age profile and the built form, but also the built environment in which the MPC is located, have impacts on the MPC residents' perceived neighbourhood boundaries.

\section{Mixed-age MPC developments}

Compared to their counterparts from age-segregated MPCs, mixed-age MPC participants put less emphasis on their social ties within the MPC to define their neighbourhood boundaries. These participants, particularly those living in high-rise apartments, had a smaller number of strong, weak and absent ties with other residents of the MPC, and their social network tended to be spread out beyond the physical boundaries of the MPC developments. The main reason was that not many residents of the mixed-age MPCs tended to have constant involvement in the social events and activities offered by the developments. This was the case because a considerable number of the residents of the mixed-age MPCs were from younger age cohorts. The younger participants, and particularly those working, tended to be involved in much wider communities of interest outside the MPC development and thus were less engaged with fellow residents in the MPC. In addition, the high-rise apartments, compared to the other types of MPC (i.e., gated and non-gated developments), provided the residents with fewer opportunities for social interaction, mainly because they lacked soft edges and shared open spaces where unplanned social interactions could take place.

The perceived neighbourhood boundaries of the participants living in mixed-age MPCs tended to be larger than that of participants from age-segregated MPCs. This is wellillustrated in Figures 4, 5 and 6, as the areas within the light blue lines which are associated 
with the perceived neighbourhood boundaries of mixed-age MPC participants are, in most cases, larger than the areas within the orange lines, which show the perceived neighbourhood boundaries of age-segregated MPC participants. As illustrated in these figures, mixed-age MPC participants referred to more than one node in defining their neighbourhood boundaries. While the MPC development comprised the main node, the other nodes included different places with physical and/or social functions. Some participants emphasised the social function of the nodes and referred to places where they socialised with other people, such as different clubs. These were particularly people who tended to be older, less mobile, with limited or a lack of driving capability. Among them were also people who moved from other cities/suburbs and left their social networks beyond. They thus established new social networks with other residents in their close proximity through different clubs and the like. Some participants also emphasised the nodes which had a physical function and referred to places such as shopping centres which they attended regularly, or areas within which they could walk easily and frequently. These participants had social networks extended to their perceived neighbourhood boundary and tended to be younger, socially and physically active, and have lived in the area for a long time. Sarah, for instance, said:

My neighbourhood is as far as I can walk on my own. So I walk down to the Brickworks [shopping precinct] about two or three times a week because I go down there and do a little bit of shopping, go and have a look at the clothing place there. Or the other place I go is down the hill and to the little shops down that way, Alicia Street.

\section{Conventional suburbs}

In contrast to MPC participants, residents of conventional suburbs defined their neighbourhood mainly in physical terms, as a geographic area. The social ties of conventional suburb participants were not concentrated in close proximity to their residences. They were rather spread out throughout the case study area and even beyond it. Therefore, the nodes to which these participants referred were not important in their social lives. Participants living in conventional suburbs emphasised the nodes which had physical functions in defining their neighbourhood boundaries. Mona, for instance, said:

I can't comment on the people because my friends aren't really in my little area. But the neighbourhood is what appeals to me. The open spaces and 
reserves, places to walk and general facilities like shopping are handy. I can walk to U3A [University of the Third Age] for instance. I can walk, it's easy. It's easy living where I'm living in my residence. Easy to access and good facilities, that's what I think.

In general, conventional suburb participants tended to have larger perceived neighbourhoods than their counterparts from MPC developments. As illustrated in Figures 4, 5 and 6, the perceived neighbourhood boundaries drawn in dark blue are, in most cases, larger than the areas within the light blue and orange lines, which were drawn by MPC participants. The main reason was that participants living in conventional suburbs referred to more than one node when defining their neighbourhoods. The nodes included various public places located in different parts of the case study areas or even beyond them. In the majority of cases the nodes included at least one local shopping centre, mainly because, as participants reported, they attended it more frequently than other places outside their homes. The other nodes usually included the public library, and a park or a green space where they could go for a walk. Only in a few cases did conventional suburb participants refer to some nodes which had social functions in defining their perceived neighbourhood boundaries. These included senior citizen centres and different clubs, particularly those which were exclusive to older people. Dena stated:

So my neighbourhood, I guess my life revolves around this area here. This area here is where I do a lot of my activities ... because my activity revolves around going to church in Eugaree Street and Nerang Street... Doing some shopping at Australia Fair, but then I do do a lot of shopping down at Aldi down here at Southport Park. So this close-ish sort of area is where I would consider as my neighbourhood.

\section{Neighbourhood nodes and the physical and social attributes of participants}

As noted, the built-form pattern was not the sole determinant of the perceived neighbourhood boundaries of the participants. The personal characteristics of the participants, including their level of physical and social activity, was also found to be of importance. Participants with health concerns and mobility limitations and those who were not driving tended to have a 
restricted physical area in which they functioned. They referred to a lower number of nodes and were likely to perceive that their neighbourhoods covered smaller areas. This was more likely to be seen among participants who were in the older age bracket (85 years or over). Examples of these participants with a restricted physical area of functioning are shown in Figure 5 (Hope Island). Note the perceived neighbourhood boundaries of two participants from mixed-age MPCs (in light blue) which are restricted to a small number of houses surrounding their own homes.

In addition, participants' personal attitudes to social engagement activities were found to be of importance in the way they defined their neighbourhood boundaries. There were some participants from age-segregated MPCs, who were very socially active outside the developments. Their high level of social engagement with people outside the developments usually stemmed from doing voluntary work or having lived in the current area for a long time. As a result, they have established a lot of social ties with other people outside the MPCs. These people thus referred to a larger number of nodes and had larger perceived neighbourhood boundaries. For example, Thomas and Helen, residents of an age-segregated MPC in Hope Island, said as a result of their social ties with a lot of people in different places outside the MPC development, they considered the whole of Hope Island to be their neighbourhood. Thomas and Helen's perceived neighbourhood boundary, which is the same as the boundary of Hope Island, is illustrated in Figure 5 (in orange). 


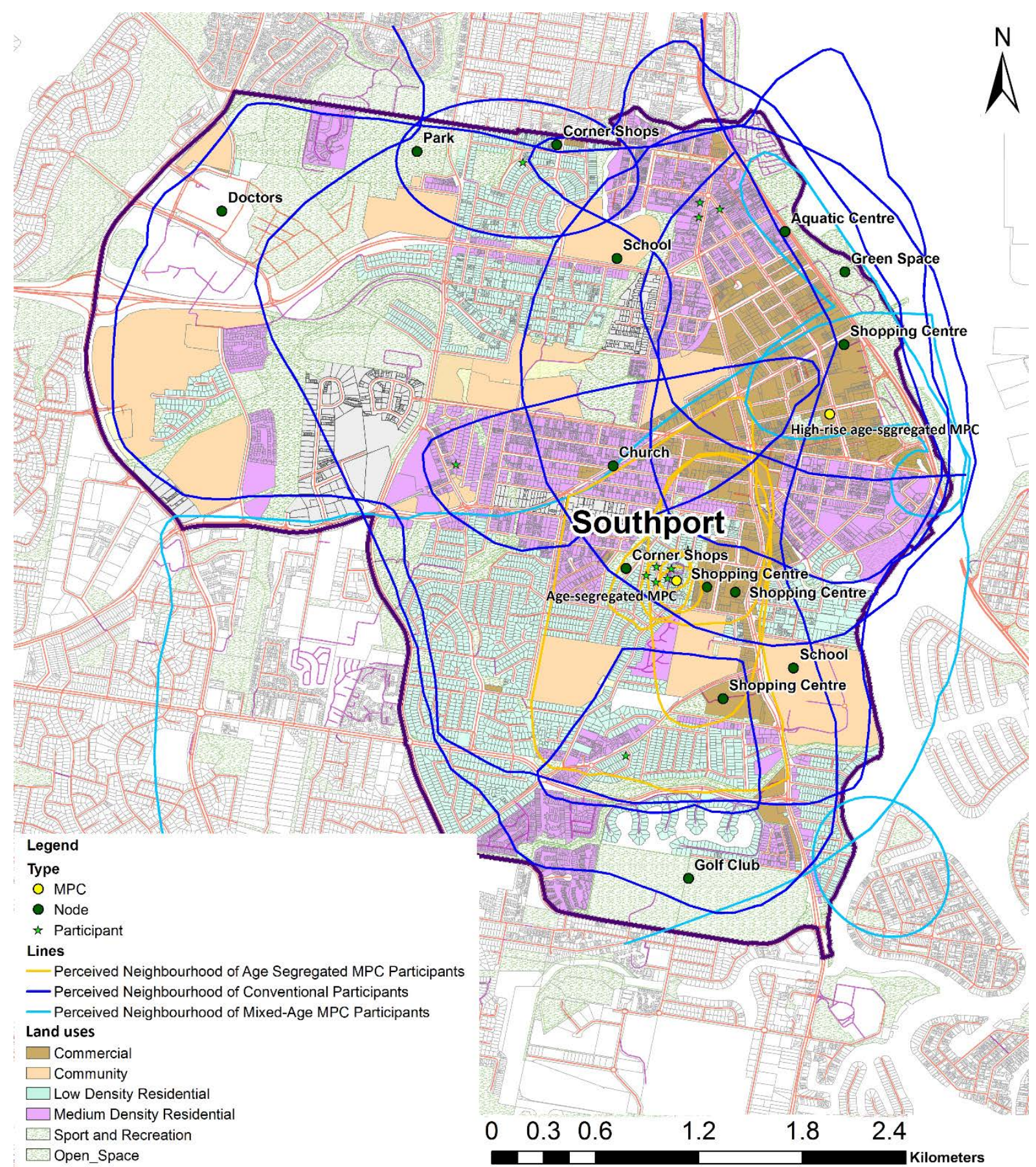

Figure 4. The map of Southport showing the land use mixture, the residences of some participants, their neighbourhood nodes, and their perceived neighbourhood boundaries. 


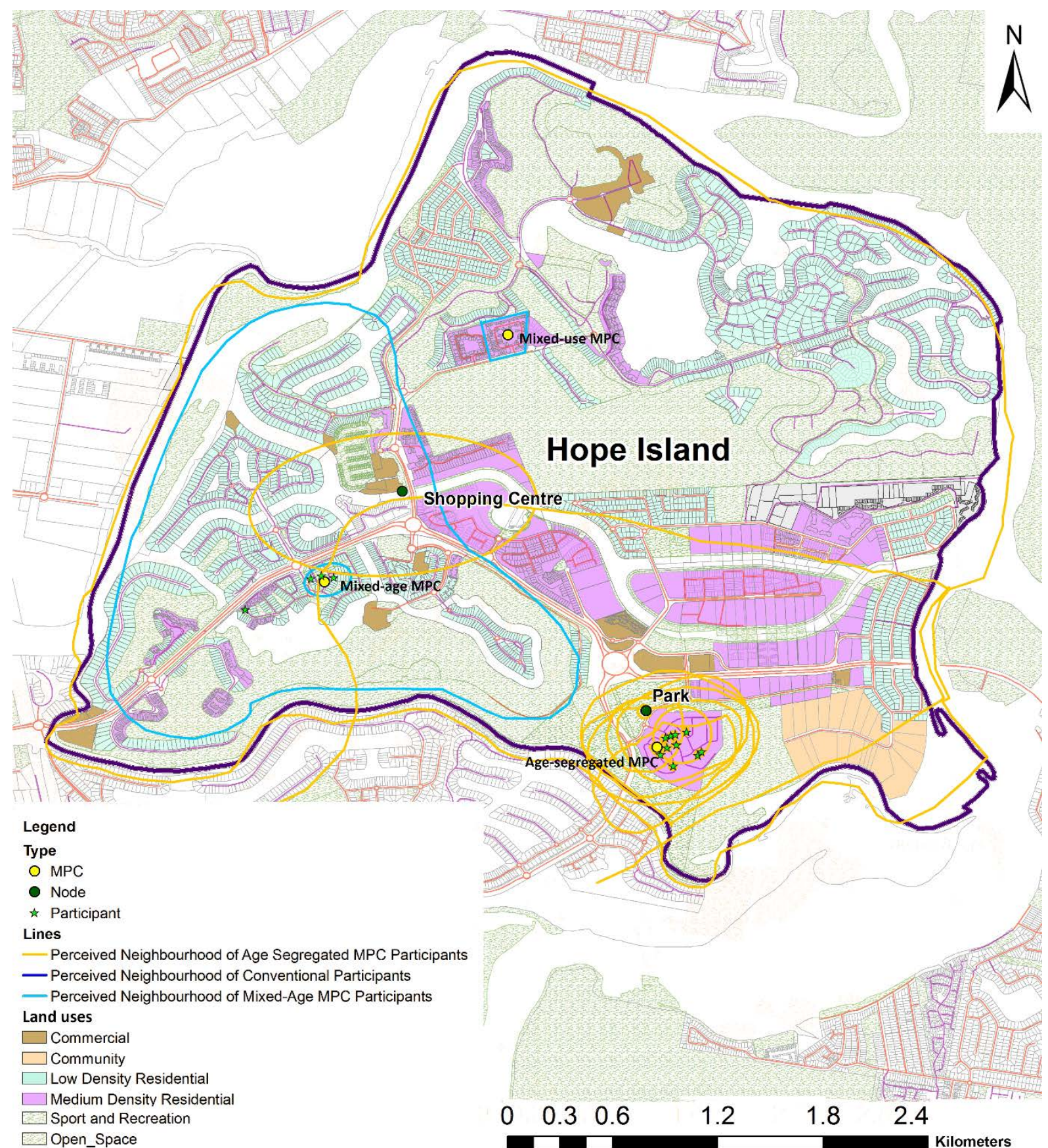

Figure 5. The map of Hope Island showing the land use mixture, the residences of some participants, their neighbourhood nodes, and their perceived neighbourhood boundaries. 


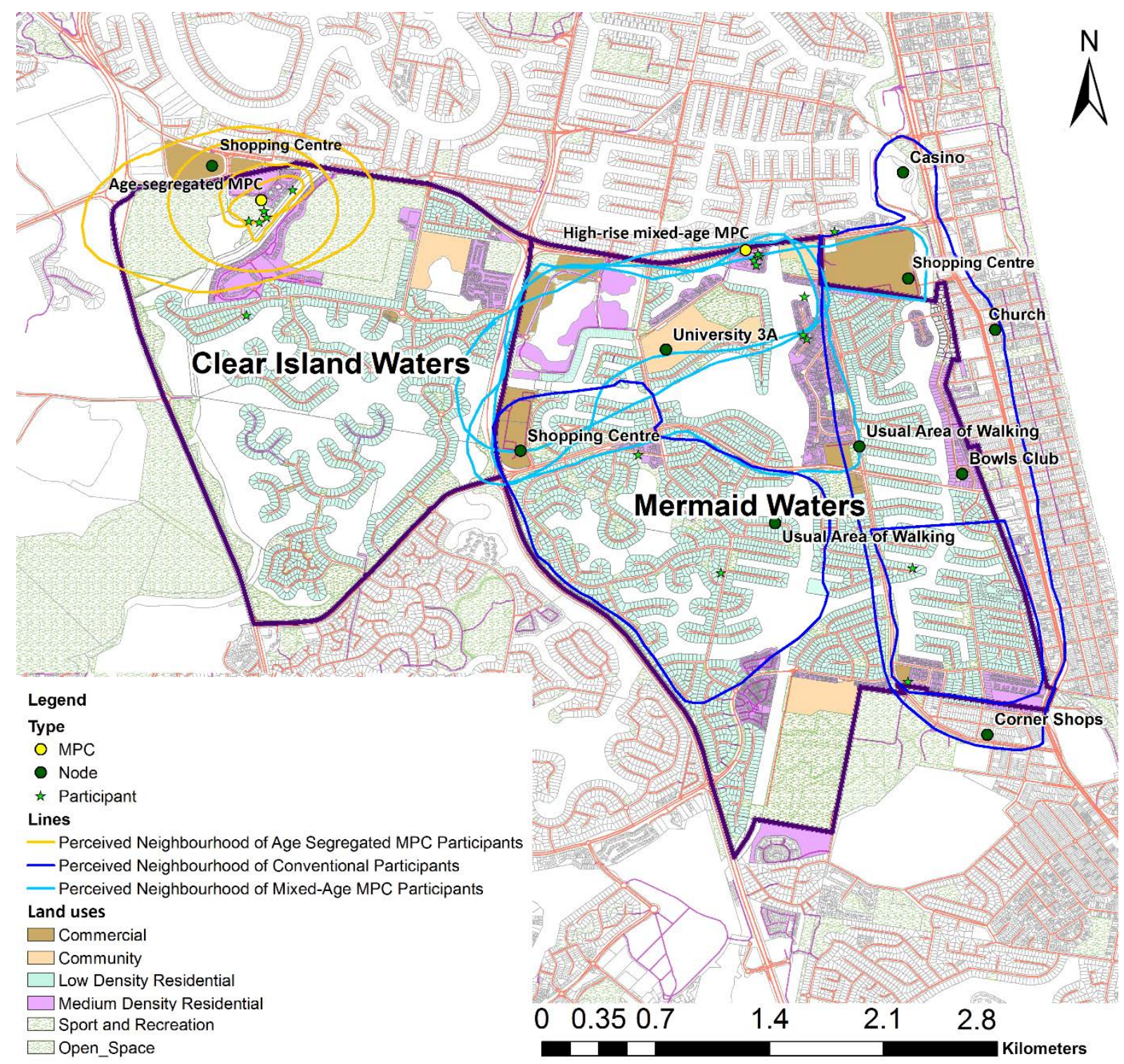

Figure 6. The map of Mermaid Waters (right) and Clear island Waters (left) showing the land use mixture, the residences of some participants, their neighbourhood nodes, and their perceived neighbourhood boundaries. 


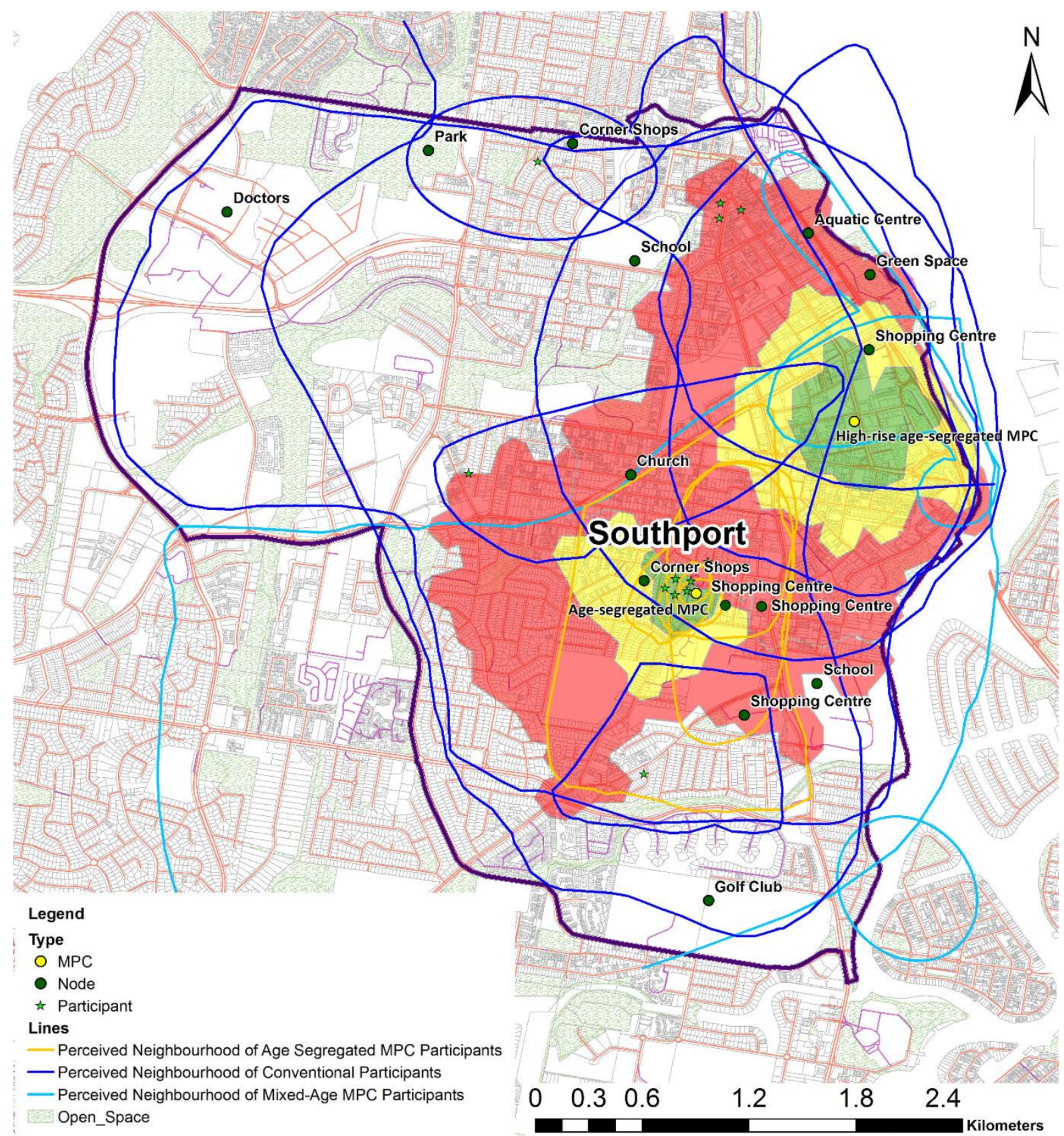

Figure 7. The map of Southport showing the walking distance service areas of 400m, 800m and $1600 \mathrm{~m}$ from each MCP development, the residences of some participants, their neighbourhood nodes, and their perceived neighbourhood boundaries. 


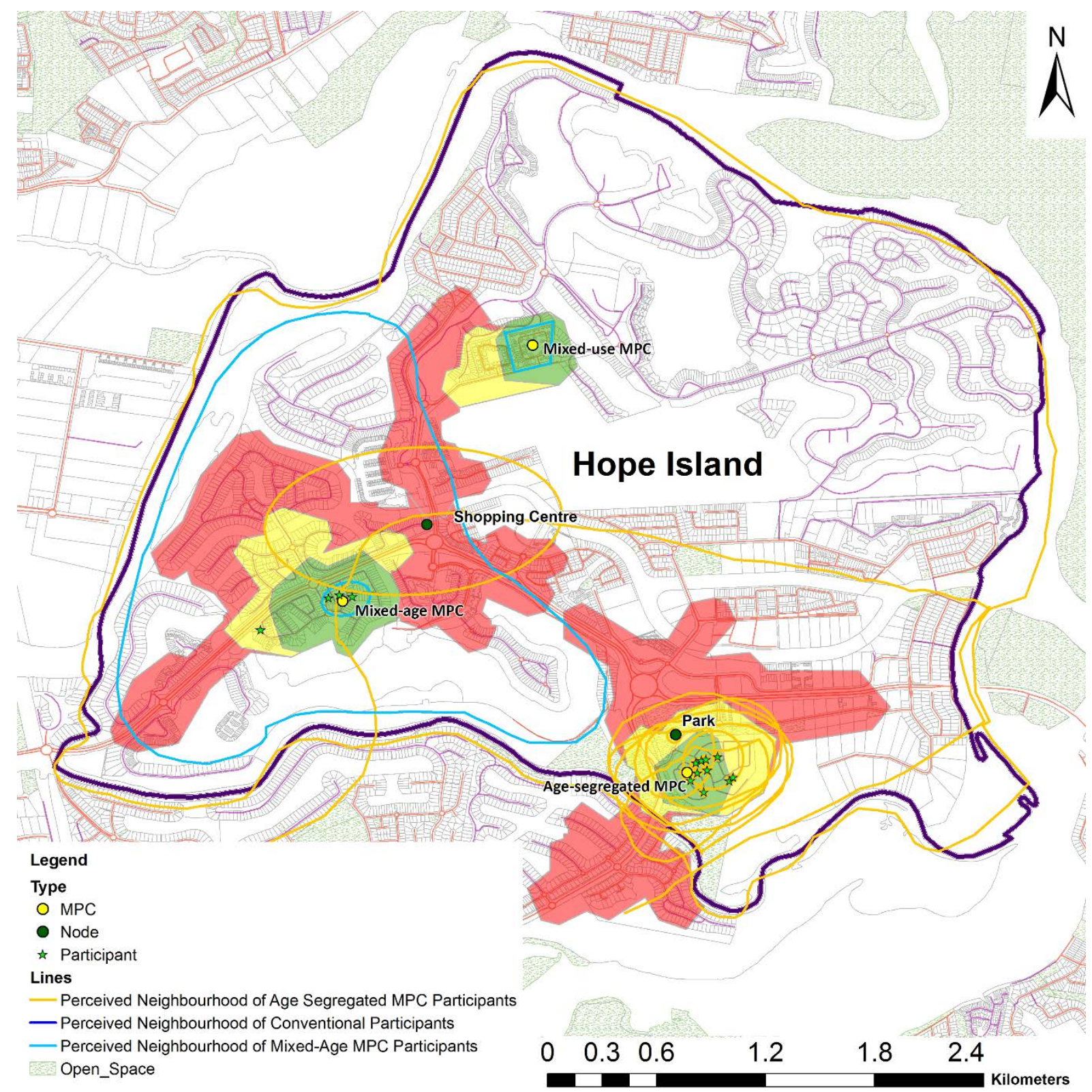

Figure 8. The map of Hope Island showing the walking distance service areas of 400m, 800m and $1600 \mathrm{~m}$ from each MCP development, the residences of some participants, their neighbourhood nodes, and their perceived neighbourhood boundaries 


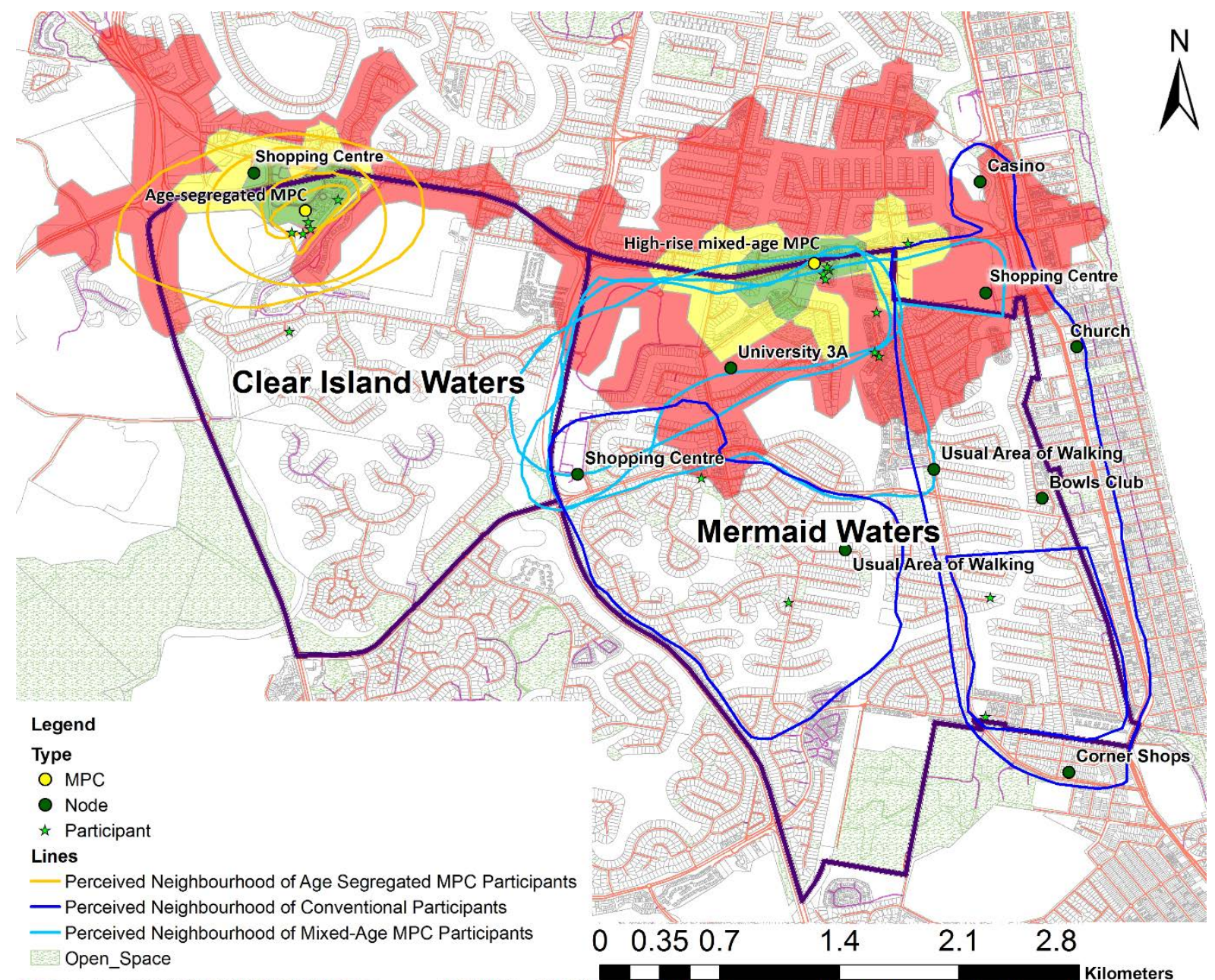

Figure 9. The map of Mermaid Waters (right) and Clear island Waters (left) showing the walking distance service areas of 400m, 800m and $1600 \mathrm{~m}$ from each MCP development, the residences of some participants, their neighbourhood nodes, and their perceived neighbourhood boundaries.

\section{So where is the neighbourhood boundary?}

The findings of this research obviously do not, and were not aimed to, lead to unambiguously bounding older people's neighbourhoods. They rather revealed some factors that contribute to how older people perceive their neighbourhood boundaries: the built form pattern in which they are living, the spatial distribution of their social networks, and their personal attributes. These factors are in line with Galster's (2001) definition of the neighbourhood: a cluster of spatial attributes associated with a group of residents as perceived by them. In order to bound the neighbourhood, Galster (2001) referred to people's 'externality space' as the area which defines their neighbourhood boundary. According to Galster (2001), people’s externality space is "the area over which changes in one or more spatially based attributes initiated by others are perceived as altering the well-being (use value, psychological and/or financial 
benefits) the individual derives from the particular location” (Galster 2001). Galster formulated three (quantifiable) features of these externality spaces: 'congruence', 'generality', and 'accordance' which can explain the findings of our research too. Congruence refers to the degree to which a person's externality spaces correspond to predetermined geographical boundaries. Generality, on the other hand, refers to the degree of correspondence between a person's externality spaces for different spatially based attributes. Finally, accordance refers to the degree of correspondence of the externality spaces for different persons who are located in close proximity (Galster 2001).

In our research, levels of generality and accordance can be seen among the perceived neighbourhood boundaries (neighbourhood externality spaces) of participants living in the same built-form pattern and with the similar levels of social and physical activities. The findings, however, stressed a low level of congruence, meaning that older people's perceived neighbourhood boundaries (neighbourhood externality spaces) did not correspond to the predetermined neighbourhood boundaries (SA2) in which they were living.

Although participants tended to define their neighbourhoods differently, the majority of them believed that their perceived neighbourhood boundary was smaller than the SA2 in which they were living (note that the SA2 boundary is shown as a purple line, being the outer boundary for each case study area). In spite of the extensive use of SA2 as the neighbourhood proxy in the current literature, only $9 \%$ of our participants referred to the SA2 as their neighbourhood. The majority of this $9 \%$ were people from Hope Island. Two factors were found to cause these participants to consider the boundary of Hope Island as their neighbourhood boundary: firstly, having a high level of social engagement outside the MPC developments and secondly, the prominent boundary of Hope Island being an actual island, physically separated from its surrounding areas. In $88 \%$ of the cases, the participants' perceived neighbourhood boundaries were smaller than the SA2 in which they were residing. This is in contrast to Coulton et al.'s (2001) research which found that the average size of the resident-defined neighbourhoods was almost the same as the census-defined neighbourhoods. What can explain the difference in our findings is the difference in the age structure of our participants. In Coulton et al.'s (2001) research, participants were all parents of young children and thus from a younger age cohort. Younger and specifically working people have a broader activity pattern and thus their perceived neighbourhood is likely to be larger than that perceived by older people. The retirement lifestyle, along with the health concerns and 
mobility limitations of those of older age, is likely to lead to restrictions in their physical area of functioning, and thus they have smaller perceived neighbourhoods.

Our findings suggest that SA2 is unlikely to be an appropriate representation of the neighbourhood for the majority of our participants, and it questions the validity of the findings of the studies which have used the SA2 as a proxy for the neighbourhood in research about older people. Our findings also suggest a review of the delivery of neighbourhood services and amenities at an SA2 level as they are not necessarily accessible to all older people and do not necessarily accommodate the needs of the older population. Smaller geographic units with consistent built-form patterns are more likely to represent the perceived neighbourhood boundaries of older people.

\section{Conclusion}

There is a growing body of research showing that the concept of the neighbourhood is laden with positive values for residents and particularity for older age cohorts. This paper explored the neighbourhood boundaries as subjective constructed units defined by 54 older people living in different built-form patterns, located in the city of the Gold Coast, Queensland, Australia. Data was collected through interviews with older people, with further evidence gathered by mapping their perceptions of their neighbourhood boundaries and the spatial distribution of their social networks. The research findings demonstrated the importance of the built-form pattern in which older people are residing, the spatial distribution of their social networks, and their personal social and physical attributes to the way they perceive the boundary of their neighbourhoods.

According to the research findings, the participants in this study used different features of the environment to define their neighbourhood boundaries. These features were in line with the five elements of the individuals' mental maps of the urban environment introduced by Lynch (1960): paths, edges, districts, nodes and landmarks. Nodes were the only feature used by almost all participants in defining their neighbourhood boundaries. MPC residents tended to refer to the nodes which had social functions. A lot of them, particularly those who were residing in age-segregated MPCs, referred to the MPC development where a great deal of their social ties have been formed and maintained, as the main node defining their neighbourhood boundaries. Participants from conventional suburbs tended to refer to nodes 
which had physical functions. These nodes included different places they attended regularly to undertake activities such as shopping and walking.

In general, MPC residents tended to have smaller perceived neighbourhoods than the residents of conventional suburbs. The size of the perceived neighbourhood varied among MPC participants with regard to the type of MPC in which they were living. Participants from age-segregated developments tended to have smaller perceived neighbourhoods than the participants from mixed-age developments. Independent of the built-form pattern, participants who had health and mobility limitations and those who did not drive, tended to have a restricted area in which to function and thus smaller perceived neighbourhood boundaries. On the other hand, participants with a high tendency towards social engagement with other people were likely to have larger perceived neighbourhoods. These particularly included older people who were doing voluntary work and those who had lived in their current areas for a long time.

Our research contributes to the growing body of research into the relationships between neighbourhood and older people in several important ways. Firstly, it supports the emergent body of knowledge on the importance of a definition of neighbourhood boundaries, which has been relatively under-researched to date. This research adds a greater level of understanding to the factors related to the ways in which older people define their neighbourhood boundaries. These findings can be utilised for land use planning and decisions concerning the location of different social and physical infrastructure targeting particular population groups in cities. Secondly, the research findings that older people from different built-form patterns define their neighbourhood boundaries differently, suggests the need to rethink neighbourhood boundaries in future research into the neighbourhood impacts on residents. The most often chosen neighbourhood proxy, at SA2 level, is not likely to represent the neighbourhood boundary of older people. Heterogeneity of the built forms within an SA2 suggests a need to define neighbourhoods of smaller sizes with consistent built forms. Finally, the built-form pattern is not the only vital component of the definition of neighbourhood boundary. There are, as illustrated in this research, other important factors such as the personal characteristics of older people, which need to be considered in order to define the neighbourhood boundary in a way which is closer to how the residents define it. In this way, an investigation of the neighbourhood's effects and the person-neighbourhood relationship is likely to be more realistic and the research findings are likely to be more trustworthy. 


\section{References}

ABS (Australian Bureau of Statistics). 2011a. Census dictionary, 2011, No. 2901.0. Canberra: ABS.

ABS (Australian Bureau of Statistics). 2011b. 2011 Census quickstats. Canberra: ABS.

Badland, H., M. White, G. MacAulay, S. Eagleson, S. Mavoa, C. Pettit, and B. Giles-Corti. 2013. "Using agent-based modelling to inform neighbourhood walkability.” In Spatial data access and integration to support liveability: A case study in North West Melbourne, edited by A. Rajabifar, and S. Eagleson, 23-37. Melbourne: University of Melbourne.

Balfour, J. L., and G. A. Kaplan. 2002. “Neighborhood environment and loss of physical function in older adults: Evidence from the Alameda County Study.” American Journal of Epidemiology 155 (6): 507-515.

Berg, B. L., and H. Lune. 2004. Qualitative research methods for the social sciences. Boston: Pearson.

Blakely, E. J., and M. G. Snyder. 1997. Fortress America: Gated communities in the United States. Washington, DC: The Brookings Institution.

Campbell, E., J. R. Henly, D. S. Elliott, and K. Irwin. 2009. "Subjective constructions of neighborhood boundaries: Lessons from a qualitative study of four neighborhoods.” Journal of Urban Affairs 31(4): 461-490.

Cheshire, L., P. Walters, and R. Wickes. 2010. "Privatisation, security and community: How master planned estates are changing suburban Australia.” Urban Policy and Research 28 (4): 359-373.

Coulton, C. J., J. Korbin, T. Chan, and M. Su. 2001. “Mapping residents' perceptions of neighborhood boundaries: A methodological note.” American Journal of Community Psychology 29 (2): 371-383.

Davies, W. K. D., and D. T. Herbert. 1993. Communities within cities: An urban social geography. New York: Belhaven Press.

Dietz, R. D. 2002. "The estimation of neighborhood effects in the social sciences: An interdisciplinary approach.” Social Science Research 31 (4): 539-575.

Dowling, R., and P. McGuirk. 2005. "Situating master planned estates: Changing city structures.” Paper presented at the State of Australian Cities National Conference, Griffith University, Brisbane, Australia, November 30-December 2. 
Downs, R. M., and D. Stea. 2011. "Cognitive maps and spatial behavior: Process and products.” In The map reader: Theories of mapping practice and cartographic representation, edited by M. Dodge, R. Kitchin, and C. Perkins, 312-317. Chichester: John Wiley \& Sons, Ltd.

Duncan, D. T., I. Kawachi, S. Subramanian, J. Aldstadt, S. J. Melly, and D. R. Williams. 2014. "Examination of how neighborhood definition influences measurements of youths' access to tobacco retailers: A methodological note on spatial misclassification.” American Journal of Epidemiology 179 (3) 373-381.

Flowerdew, R., D. J. Manley, and C. E. Sabel. 2008. “Neighbourhood effects on health: Does it matter where you draw the boundaries?” Social Science \& Medicine 66 (6):12411255.

Galster, George. 2001. “On the nature of neighbourhood.” Urban Studies 38 (12) 2111-2124.

Gehl, J. 1986. “ “Soft edges” in residential streets.” Scandinavian Housing and Planning Research 3 (2): 89-102.

Gibbons, S. 2002. Neighbourhood effects on educational achievement. London: Centre for the Economics of Education, London School of Economics and Political Science.

Godfrey, M., J. Townsend, and T. Denby. 2004. Building a good life for older people in local communities: The experience of ageing in time and place. York: Joseph Rowntree Foundation.

Goux, D., and E. Maurin. 2007. “Close neighbours matter: Neighbourhood effects on early performance at school.” The Economic Journal 117 (523): 1193-1215.

Granovetter, M. S. 1973. “The strength of weak ties.” American Journal of Sociology 78 (6): 1360-1380.

Grant, J., and L. Mittelsteadt. 2004. “Types of gated communities.” Environment and Planning B: Planning and Design 31 (6): 913-930.

Guest, A. M., and B. A. Lee .1984. "How urbanites define their neighborhoods.” Population and Environment 7 (1): 32-56.

Keller, S. I. 1968. The urban neighborhood: A sociological perspective. New York: Random House.

Lebel, A., R. Pampalon, and P. Y. Villeneuve. 2007. “A multi-perspective approach for defining neighbourhood units in the context of a study on health inequalities in the Quebec City region.” International Journal of Health Geographics 6 (27). doi: 10.1186/1476-072X-6-27. 
Lee, B. A., and K. E. Campbell. 1997. "Common ground? Urban neighborhoods as survey respondents see them.” Social Science Quarterly 78 (4): 922-936.

Lupton, R. 2003. Neighbourhood effects: Can we measure them and does it matter? London: Centre for Analysis of Social Exclusion, London School of Economics.

Lynch, K. 1960. The image of the city. Cambridge: MIT press.

McCulloch, A., and H. E. Joshi. 2001. "Neighbourhood and family influences on the cognitive ability of children in the British National Child Development Study.” Social Science \& Medicine 53 (5): 579-591.

Meegan, R., and A. Mitchell .2001. “' It's not community round here, it’s neighbourhood': Neighbourhood change and cohesion in urban regeneration policies.” Urban Studies 38 (12): 2167-2194.

Minnery, J., and B. Bajracharya. 1999. "Visions, planning processes and outcomes: Master planned communities in South East Queensland.” Australian Planner 36 (1): 33-41.

Orford, S., and C. Leigh. 2014. "The relationship between self-reported definitions of urban neighbourhood and respondent characteristics: A study of Cardiff, UK.” Urban Studies 51 (9): 1891-1908.

Oswald, F., A. Hieber, H. Wahl, and H. Mollenkopf. 2005. “Ageing and person-environment fit in different urban neighbourhoods.” European Journal of Ageing 2 (2): 88-97.

Park, R. E., E. W. Burgess, and R. D. McKenzie. 1925. The city. Chicago: University of Chicago Press.

Phillips, D. R., O. Siu, A. G. Yeh, and K. H. C. Cheng. 2005. “Ageing and the urban environment.” In Ageing and place: Perspectives, policy, practice, edited by G. J. Andrews, and D. R. Phillips, 147-163. London: Routledge.

Rybczynski, W. 1995. City life: Urban expectations in a new world. New York: Simon and Schuster.

Sampson, R. J., J. D. Morenoff, and T. Gannon-Rowley. 2002. “Assessing "neighborhood effects”: Social processes and new directions in research.” Annual Review of Sociology 28: 443-478.

Smith, G., C. Gidlow, R. Davey, and C. Foster. 2010. "What is my walking neighbourhood? A pilot study of English adults' definitions of their local walking neighbourhoods.” International Journal of Behavioral Nutrition and Physical Activity 7 (34). doi:10.1186/1479-5868-7-34.

Spielman, S. E., and E. Yoo. 2009. “The spatial dimensions of neighborhood effects.” Social Science \& Medicine 68 (6): 1098-1105. 
Weiss, L., D. Ompad, S. Galea, and D. Vlahov. 2007. “Defining neighborhood boundaries for urban health research.” American Journal of Preventive Medicine 32 (6): S154-S159.

Yen, I. H., Y. L. Michael, and L. Perdue. 2009. "Neighborhood environment in studies of health of older adults: A systematic review.” American Journal of Preventive Medicine 37 (5): 455-463.

Ziersch, A. M., F. E. Baum, C. MacDougall, and C. Putland. 2005. "Neighbourhood life and social capital: The implications for health.” Social Science \& Medicine 60 (1): 71-86. 